\title{
Bioedusiana
}

Blölogy

http://jurnal.unsil.ac.id/index.php/bioed

DOI: https://doi.org/10.37058/bioed.v6i2.3249

\section{Mempromosikan Literasi Biologi kepada Siswa Sekolah Menengah: Pengembangan Instrumen Tes untuk Kelas VII}

\section{Promoting Biological Literacy to Middle School Students: Development of Test Instruments for Class VII}

\author{
Vonny ${ }^{1 *}$, Khairotun Nihlah ${ }^{2}$, Mieke Miarsyah $^{3}$, Rizhal Hendi Ristanto $^{4}$ \\ 1,2,3,4 Prodi Magister Pendidikan Biologi, Universitas Negeri Jakarta, Jalan Pemuda No.28, Rawamangun, \\ Kota Jakarta Timur, 13220
}

\begin{abstract}
Abstrak
Praktik pendidikan di setiap jenjang sekolah, selayaknya memenuhi tantangan abad ke-21. Literasi sains merupakan salah satu keterampilan penting yang harus dikembangkan sejak tahap awal pendidikan. Pada penelitian ini, instrumen untuk menilai keterampilan literasi biologi siswa SMP dikembangkan dan divalidasi. Pengembangan instrumen ini menerapkan tahapan model ADDIE. Instrumen ini dirancang berdasarkan kompetensi dasar IPA Biologi kurikulum 2013 untuk kelas VII, dan terdiri dari empat dimensi literasi Biologi. Dari 20 soal yang dikembangkan, terdapat 5 soal berdimensi nominal, 7 soal berdimensi fungsional, 4 soal berdimensi struktural dan 4 soal literasi biologi multidimensi. Uji validitas logis dilakukan untuk isi, konstruksi dan bahasa oleh empat validator, dan dianalisis dengan formula Aiken. Validitas empiris dilakukan dengan uji coba soal kepada 82 siswa kelas VII SMPN 3 Parung Panjang dan dianalisis menggunakan korelasi point biserial. Hasil analisis memperoleh 19 soal valid dan 1 soal tidak valid. Reliabilitas soal diuji menggunakan rumus Kuder Richardson 20, dan diperoleh nilai 0,57 yang berarti instrumen ini cukup reliabel. Tingkat kesulitan setiap soal juga dianalisis, dan diperoleh hasil dengan proporsi $70 \%$ soal memiliki tingkat kesulitan sedang dan 30\% soal memiliki tingkat kesulitan tinggi.
\end{abstract}

Kata kunci: Instrumen Tes Literasi; Literasi Biologi; Literasi Sains

\section{Abstract}

Education practices in every level should meet the $21^{\text {st }}$ century challenge. Scientific literacy is one crucial skill that should be developed from an early stage of education. In this study, an instrument to assess lower middle school students' skill on biology literacy was developed and validated. The development of this instrument was carried out using the ADDIE model. This instrument was designed based on grade seven's Biology basic competences of Indonesian 2013 curriculum and consists of four dimensions of Biological literacy. There were 5 items of nominal dimension, 7 items of functional dimension, 4 items of structural dimension and 4 items of multidimensional dimension of biology literacy. Logical validity test was done for content, construct, and language by four validators, and was analyzed by Aiken's formula. Concurrent validity was subsequently administered to 82 grade seven students of SMPN 3 Parung Panjang and analyzed using point biserial correlation that resulted in 19 valid items. The result of the reliability test using Kuder Richardson 20 formula was 0,57, which indicates this instrument was quite reliable. Difficulty level of each item was also determined, with proportion $70 \%$ items having medium difficulty level and 30\% items having high difficulty level.

Keywords: Literacy Test Instrument, Biology Literation, Sains Literacy

Article History

Received: June $2^{\text {nd }}, 2021$; Accepted: December 26 ${ }^{\text {th }}, 2021$; Published: December $31^{\text {st }}, 2021$

Corresponding Author*

Vonny, Prodi Magister Pendidikan Biologi, Universitas Negeri Jakarta, E-mail: gandawiguna.vonny@gmail.com

(C) 2021 Bioedusiana. This is an open access article under the CC BY-SA 4.0 license

(https://creativecommons.org/licenses/by-sa/4.0/)

\section{PENDAHULUAN}

Relevansi kurikulum pendidikan terhadap situasi lingkungan global dan pengaruhnya terhadap aspek sosiokultural dan ekonomi, merupakan tantangan pendidikan sains pada abad ke-21 (McFarlane, 2013). Informasi mengenai situasi nyata lingkungan global, pada era digital 
ini mudah diakses siswa melalui berbagai media secara daring. Tantangannya adalah bagaimana menumbuhkan minat baca dan keterampilan siswa dalam menyerap, mengolah dan mengintegrasikan informasi yang diperoleh dengan pengetahuan teoritis yang dipelajari di sekolah.

Implementasi isu sosio-saintifik dengan materi pembelajaran dapat meningkatkan kemampuan literasi sains pada siswa (Yenni et al., 2017). Hal ini dukung oleh penemuan (Oliveras et al., 2011) mengenai penggunaan surat kabar sebagai media dapat melatih keterampilan membaca dan mengaitkan berbagai konsep sains dengan permasalahan di dalam dunia nyata. Suprapto (2016) berpendapat bahwa siswa Indonesia masih kurang dalam hal pemahaman terhadap isu sains global, kemampuan menjelaskan fenomena sains, kemampuan mendesain perencanaan sains secara inkuiri, serta kemampuan menginterpretasikan data/bukti saintifik.

Dua penelitian yang dilakukan di sekolah menengah di Kota Sumedang (Rachmatullah et al., 2016) dan Kota Surakarta (Novaristiana et al., 2019) menemukan bahwa siswa memperoleh kategori rendah dalam kemampuan literasi sains karena ketidakmampuan siswa dalam menangkap inti dari teks atau deskripsi awal yang diberikan sebelum pertanyaan soal diberikan. Hal ini menunjukkan kurangnya minat membaca dan kurangnya pengalaman siswa dalam membaca soal yang bertipe literasi. Selain itu, buku teks yang mengimplementasikan kurikulum 2013 belum mencakup semua komponen kompetensi literasi sains secara proporsional dan hanya menekankan penjelasan fenomena sains secara teoritis (Lasminawati et al., 2019; Wahyu et al., 2016). Hal ini juga menjadi alasan rendahnya kemampuan literasi siswa Indonesia pada umumnya.

Literasi memiliki keterkaitan yang sangat erat dengan aktivitas kegiatan membaca dan menulis dalam konteks apapun. Keterampilan literasi dapat diaplikasikan dalam berbagai ragam aspek keilmuan. Salah satunya adalah literasi sains yang dapat dimanfaatkan dalam memahami dan memecahkan masalah kehidupan sehari-hari (Suwono et al., 2017). Kemampuan literasi sains merupakan keterampilan yang perlu diajarkan dan dilatih untuk membangun koneksi antara pengetahuan dan keterampilan siswa terhadap fenomena aktual yang terjadi di sekitar mereka (Seddon, 2017). Pernyataan ini juga diperkuat oleh sebuah penelitian, bahwa belajar Biologi dengan menggunakan pendekatan saintifik dapat melatih dan meningkatkan kemampuan literasi sains Biologi dari kategori rendah menjadi kategori medium (Setiawan, 2019b). Selain itu, investigasi berbasis teks telah terbukti dapat membantu baik guru sains maupun siswanya untuk mengembangkan kemampuan literasi sains atau pengetahuan dan konsep sains (Greenleaf et al., 2011).

Salah satu cabang literasi sains adalah literasi biologi. Literasi biologi membutuhkan pemahaman tentang hakikat sains (Penick, 2000). Literasi ini yang dapat membantu siswa dalam 
memahami konten, khususnya biologi. Literasi biologi adalah kemampuan menggunakan inkuiri ilmiah untuk memahami dan mengenali isu-isu biologis dalam masyarakat dan mengintegrasikan ide-ide tersebut ke dalam pengambilan keputusan dan mengkomunikasikan hasilnya kepada orang lain (McBride et al., 2013). Individu yang mempunyai penguasaan dalam literasi biologi maka memiliki kemampuan dalam menyelesaikan masalah dengan mempergunakan konsep-konsep sains yang didapat dalam pendidikan yang sepadan dengan tingkatannya.

Esensi dari literasi biologi adalah memahami prinsip biologis secara mendalam dan menerapkannya dengan cara yang tepat salah satunya dengan terlibat dalam diskusi, mencari informasi biologis yang valid, menafsirkan tabel dan gambar yang diterbitkan, dan membuat keputusan pribadi dan masyarakat (Demastes \& Wandersee, 1992). Maka dengan kata lain, literasi biologi berfokus pada penggunaan konsep-konsep kunci dalam biologi untuk membuat keputusan dalam memecahkan masalah melalui penyelidikan ilmiah.

Instrumen penilaian merupakan bagian yang penting dalam proses pembelajaran. Informasi penilaian selayaknya mampu memberikan informasi mengenai apa yang telah siswa pelajari dan apa yang telah guru ajarkan. Pertanyaan-pertanyaan dalam instrumen penilaian diarahkan untuk mengungkap ketercapaian tujuan pembelajaran yang telah diungkapkan (Suwarto, 2013).

Instrumen literasi sains untuk mata pelajaran Biologi, telah banyak dikembangkan pada berbagai tingkat satuan pendidikan. Sebagian besar instrumen literasi sains yang dikembangkan, berfokus pada topik-topik tertentu saja. Beberapa contoh pengembangan instrumen literasi sains pada topik tertentu adalah: 1)Instrumen literasi dengan topik keanekaragaman makhluk hidup (Putri, 2020), 2) Instrumen asesmen literasi sains dengan materi sistem pencernaan, zat aditif dan zat adiktif (Lina et al., 2018), 3) Instrumen asesmen literasi sains pada materi tekanan zat dan penerapannya (Novanti et al., 2018), 4) Instrumen literasi sains materi koordinasi (Rachmawati \& Kurniawati, 2020), 5) Instrumen penilaian untuk pembelajaran ekologi berorientasi literasi saintifik (Setiawan, 2019a), 6) Instrumen literasi saintifik untuk materi Plantae dan Animalia (Setiawan \& Mufassaroh, 2019), 7) Pengembangan instrumen penilaian kemampuan literasi sains siswa kelas xi materi sistem ekskresi dan koordinasi di SMAN 9 Malang (Hasana \& Saptasari, 2017).

Berbeda dengan berbagai instrumen literasi Biologi yang telah dikembangkan per topik, instrumen literasi Biologi yang dikembangkan ini berdasarkan pada materi-materi Biologi yang diajarkan dalam mata pelajaran IPA di SMP kelas VII. Pengembangan instrumen dilakukan pada lima kompetensi dasar kurikulum 2013 mata pelajaran IPA kelas VII. Kompetensi dasar yang dipilih adalah KD yang merupakan kompetensi mata pelajaran Biologi. Instrumen yang dikembangkan meliputi empat dimensi literasi Biologi, yaitu dimensi nominal, fungsional, 
struktural dan multidimensional (Djamahar et al., 2021; Shwartz et al., 2006; Uno \& Bybee, 1994).

\section{METODE}

Penelitian ini menggunakan jenis penelitian dan pengembangan atau Research and Development $(\mathrm{R} \& \mathrm{D})$ dengan pengembangan yang diadaptasi dari Dick and Carey pada tahun 1996 yaitu model ADDIE. Tahapan model ADDIE dapat dilihat pada Gambar 1 di bawah ini:

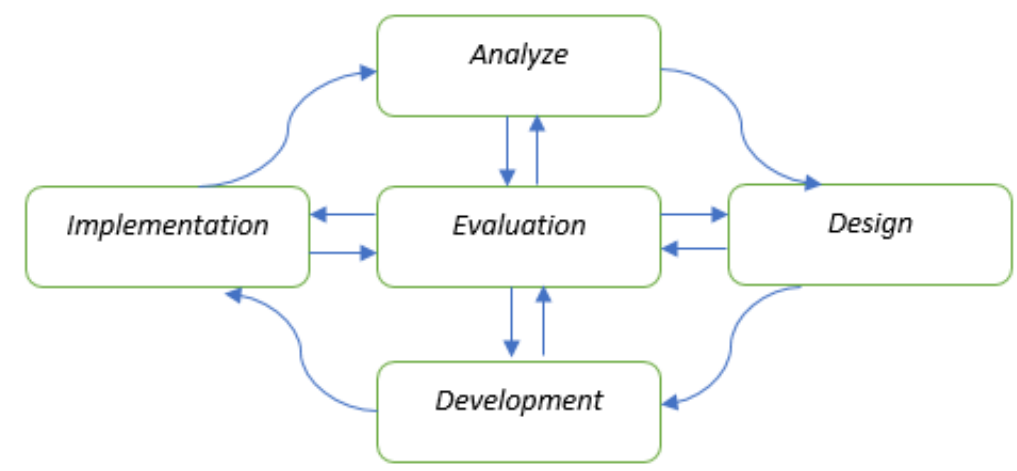

Gambar 1. Tahapan Model ADDIE (Branch, 2009)

Prosedur penelitian yang dilaksanakan yaitu dalam kelima tahapan tersebut, peneliti hanya membatasi sampai pada tahap tiga yaitu tahap pengembangan (development) dikarenakan keterbatasan pada waktu penelitian maka pada tahap implementation dan evaluation tidak dilaksanakan. Tahap yang pertama yaitu analyze, yang dilakukan oleh peneliti meliputi analisis indikator soal mulai dari kompetensi dasar, lalu analisis indikator literasi biologi terkait materi biologi SMP kelas VII. Tahap yang kedua yaitu tahap design, yang dilakukan peneliti adalah mendesain kisi-kisi instrumen tes dan kisi-kisi lembar validasi untuk validator. Tahap yang ketiga yaitu tahap development, yang dilakukan peneliti adalah mengembangkan instrumen tes dengan mengacu kepada kisi-kisi dan pengolahan rubrik penilaian serta penyusunan lembar validasi untuk mengukur kelayakan produk atau instrumen tes sebelum masuk pada tahapan implementasi. Instrumen tes yang disusun kemudian divalidasi dan dievaluasi oleh ahli materi yaitu oleh dua orang dosen dengan bidang keahlian evaluasi pembelajaran dan bidang ilmu komunikasi, serta dua orang praktisi lapangan dengan jabatan kepala litbang IPA di sekolah swasta, dan seorang guru yang berpengalaman sebagai wakil kepala sekolah bidang kurikulum.

Instrumen tes yang dikembangkan berupa tes pilihan ganda berbasis literasi berjumlah 20 butir soal. Penelitian dilaksanakan pada bulan Mei 2021 dengan subjek uji coba instrumen tes yaitu 82 siswa kelas VII di SMPN 3 Parung Panjang. Tes ini diberikan kepada siswa dengan menggunakan Google form yang terdiri dari empat bagian. Bagian pertama, kedua dan ketiga terdiri dari beberapa pertanyaan dengan topik dan dimensi yang bervariasi, namun memiliki keterkaitan dalam konteks. Hasil uji coba yang telah dilakukan kemudian dianalisis dengan menggunakan teknik point biserial, uji reliabilitas KR-20, uji daya beda butir soal dan uji tingkat 
kesulitan per butir soal. Kriteria validitas logis yang dinilai oleh empat orang pakar, ditentukan berdasarkan pada formula Aiken dengan rumus sebagai berikut:

$$
\mathrm{V}=\frac{\Sigma s}{n(c-1)}
$$

$\mathrm{V} \quad=$ kesepakatan rater mengenai validitas butir

$\mathrm{s} \quad \mathrm{r} r-10$

$\mathrm{r} \quad=$ skor kategori pilihan rater

$10=$ skor terendah dalam kategori pemberian skor

(Aiken, 1980; Atta et al., 2020; Retnawati, 2016b).

Jika indeksnya kurang atau sama dengan 0,4 dikatakan validitasnya kurang, 0,4-0,8 dikatakan validitasnya sedang, dan jika lebih besar dari 0,8 dikatakan sangat valid (Dawati et al., 2017). Validitas empiris instrumen terhadap 82 siswa kelas VII SMP dilakukan melalui validitas item butir soal, yaitu membandingkan nilai $r$ pada tiap butir soal dengan teknik korelasi point biserial. Reliabilitas soal dilakukan menggunakan rumus Kuder Richardson 20 (KR-20) (Retnawati, 2016a).

\section{HASIL DAN PEMBAHASAN}

\section{Hasil}

Tabel 1 menyajikan hasil penelitian berupa pengembangan soal literasi Biologi, dengan persebaran materi berdasarkan kompetensi dasar mata pelajaran Biologi kelas VII dan dimensi literasi Biologi. Sedangkan Tabel 2 memberikan penjelasan mengenai penyajian soal dilakukan per bagian (section) pada google form yang dilakukan sesuai dengan konteks soal yang sama.

Tabel 1. Penjabaran KD, Dimensi Literasi Biologi pada setiap Nomor Soal

\begin{tabular}{llcl}
\hline & \multicolumn{1}{c}{ Kompetensi Dasar } & $\begin{array}{c}\text { Dimensi Literasi } \\
\text { Biologi }\end{array}$ & Nomor Soal \\
\hline $\mathbf{3 . 2}$ & $\begin{array}{l}\text { Mengklasifikasikan makhluk hidup dan benda } \\
\text { berdasarkan karakteristik yang diamati. }\end{array}$ & $\begin{array}{c}\text { Nominal } \\
\text { Fungsional }\end{array}$ & S3, S4 \\
\hline $\mathbf{3 . 5}$ & $\begin{array}{l}\text { Memahami konsep energi, berbagai sumber } \\
\text { energi, dan perubahan bentuk energi dalam } \\
\text { kehidupan sehari-hari termasuk fotosintesis. }\end{array}$ & $\begin{array}{l}\text { Fungsional } \\
\text { Struktural }\end{array}$ & S10, S12 \\
\hline 3.6 & $\begin{array}{l}\text { Memahami sistem organisasi kehidupan mulai } \\
\text { dari tingkat sel sampai organisme dan komposisi } \\
\text { utama penyusun sel }\end{array}$ & Nominal \\
\hline \multirow{3}{3.7}{} & $\begin{array}{l}\text { Menganalisis interaksi antara makhluk hidup } \\
\text { dan lingkungannya serta dinamika populasi } \\
\text { akibat interaksi tersebut. }\end{array}$ & fungsional & S13, S15 \\
\hline 3.8. & $\begin{array}{l}\text { Menganalisis terjadinya pencemaran } \\
\text { lingkungan dan dampaknya bagi ekosistem }\end{array}$ & Nominal \\
\hline
\end{tabular}


Tabel 2. Bentuk Instrumen Tes yang Dikembangkan

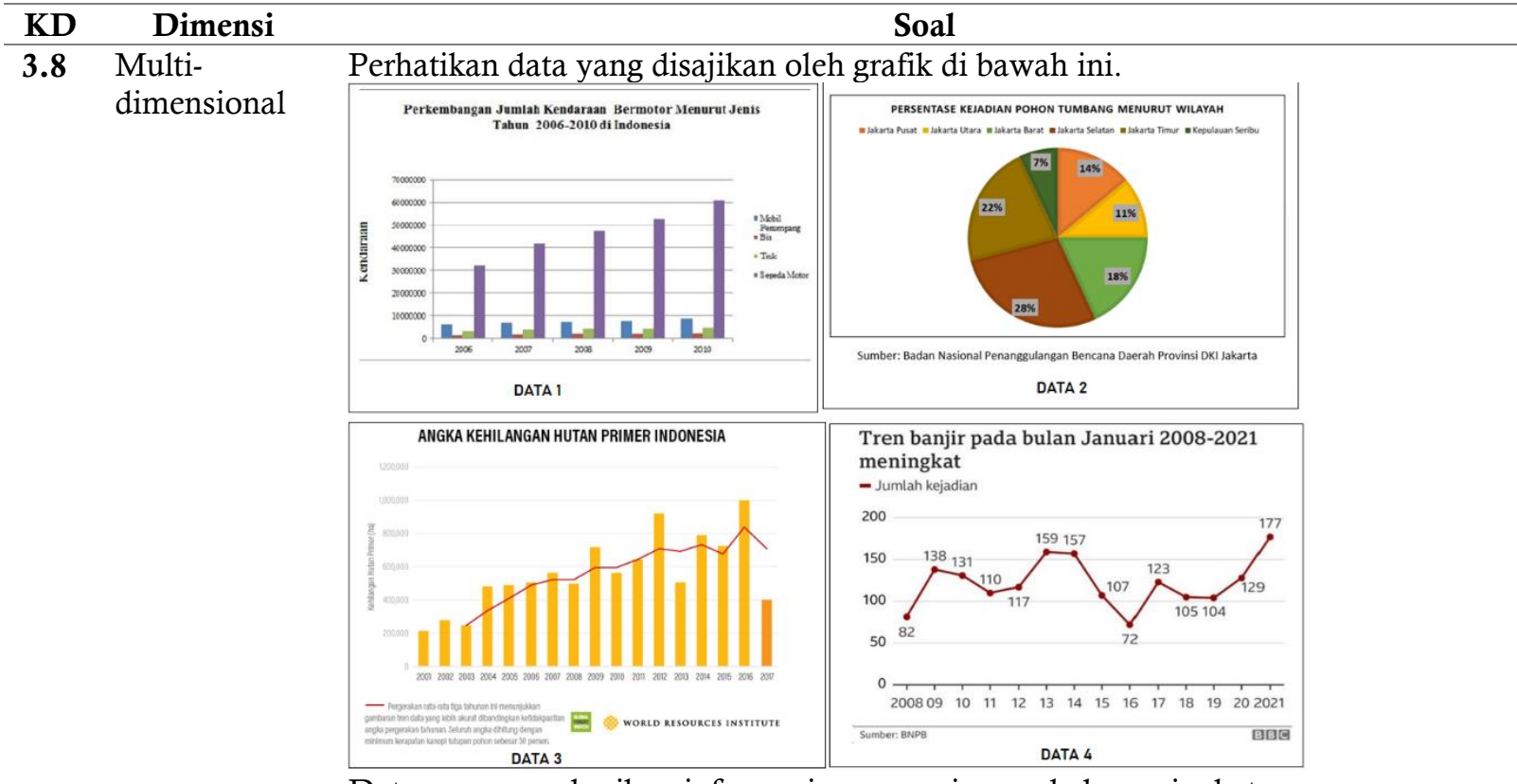

Data yang memberikan informasi mengenai penyebab meningkatnya pencemaran udara di Indonesia adalah.....
A. Data 1 dan 2
B. Data 1 dan 3
C. Data 1,2 dan 3
D. Data 1,3 dan 4

3.8 Multi-

Grafik pada data 3, menunjukkan bahwa hutan primer di Indonesia mengalami dimensional penurunan. Hutan di Indonesia saat ini semakin berkurang akibat banyaknya kegiatan penebangan lahan hutan untuk dijadikan area perkebunan kelapa sawit seperti gambar di bawah ini. Hal ini akan menimbulkan dampak negatif, karena hutan memiliki manfaat yang penting. Berbagai manfaat hutan yaitu sebagai penyedia oksigen, produsen dalam ekosistem, serta menyimpan air tanah dalam jumlah yang banyak. Apa dampak negatif yang akan terjadi dalam waktu singkat terkait dengan fungsi hutan sebagai penyimpan air, apabila penebangan liar tidak segera diatasi dengan serius?

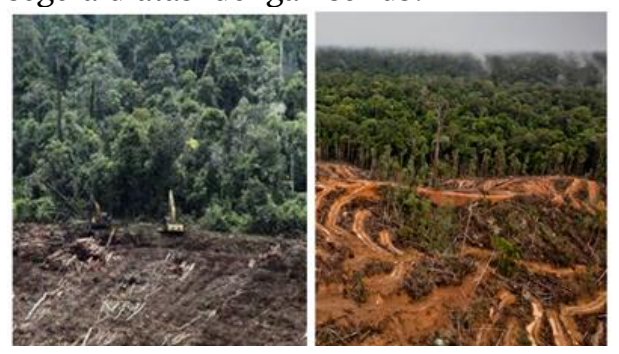

A. Kepunahan semua spesies hewan, tumbuhan, dan mikroorganisme di hutan.

B. Tanah menjadi tidak subur, padat dan mudah longsor.

C. Suhu lingkungan menjadi menurun.

D. Terjadi banjir di musim hujan dan mengeringnya sungai dan mata air pada musim kemarau. 
3.7 Nominal Di dalam hutan, terdapat berbagai organisme seperti tampak pada gambar berikut ini. Gambar yang menunjukkan sebuah populasi dan sebuah ekosistem secara berurutan adalah....

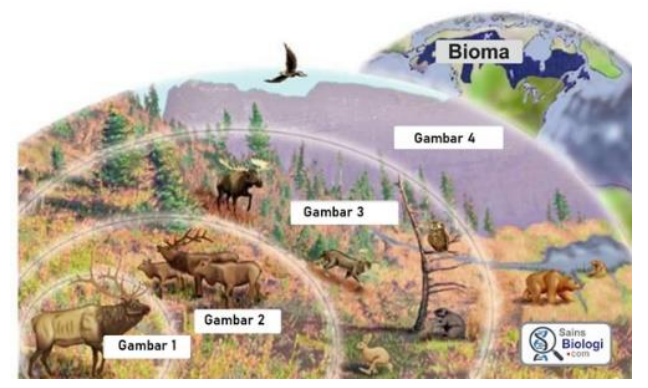

A. Gambar 3 dan 4

B. Gambar 2 dan 3

C. Gambar 1 dan 3

D. Gambar 2 dan 4

\subsection{Fungsional}

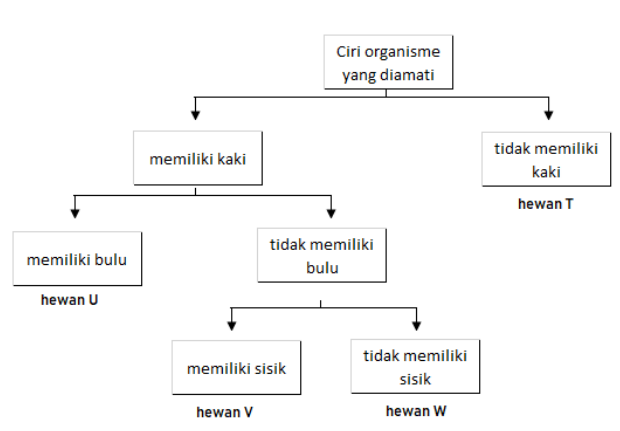

Di area hutan, terdapat banyak hewan vertebrata. Seorang siswa mengamati beberapa hewan vertebrata, lalu membuat klasifikasi dengan menggunakan diagram berikut ini. Berdasarkan diagram klasifikasi yang dibuat siswa tersebut, termasuk kelas apakah organisme $\mathrm{W}$ ?

A. Amfibi

B. Aves
C. Pisces
D. Reptilia

3.5 Fungsional Selain terdapat hewan, di hutan juga terdapat banyak tumbuhan. Yang melakukan proses fotosintesis. Urutan yang tepat proses fotosintesis dan organ yang melakukannya adalah...

Tabel berikut menunjukkan tahapan proses fotosintesis dan organ/jaringan yang terlibat.

\begin{tabular}{|c|l|c|c|}
\hline No & Tahapan Proses Fotosintesis & Kode & $\begin{array}{l}\text { Jaringan/ Organ } \\
\text { pada Fotosintesis }\end{array}$ \\
\hline 1 & $\begin{array}{l}\text { Transfer hasil fotosintesis dari } \\
\text { daun ke seluruh bagian }\end{array}$ & $\mathrm{P}$ & Xylem \\
\hline 2 & Pengambilan CO2 & $\mathrm{R}$ & Stomata \\
\hline 3 & $\begin{array}{l}\text { Pengangkutan air dari akar ke } \\
\text { daun }\end{array}$ & $\mathrm{S}$ & Floem \\
\hline 4 & Penyerapan air dan mineral & $\mathrm{T}$ & Akar \\
\hline
\end{tabular}

Urutan yang tepat proses fotosintesis dan organ yang melakukannya adalah ....
A. $1 \mathrm{P}-2 \mathrm{R}-3 \mathrm{~S}-4 \mathrm{~T}$
B. $4 \mathrm{~T}-3 \mathrm{P}-2 \mathrm{R}-1 \mathrm{~S}$
C. $1 \mathrm{~S}-2 \mathrm{R}-3 \mathrm{P}-4 \mathrm{~T}$
D. $4 \mathrm{~T}-3 \mathrm{~S}-2 \mathrm{R}-1 \mathrm{P}$

Validitas logis instrumen yang dikembangkan, divalidasi dan dinilai oleh empat validator, serta dianalisis dengan menggunakan formula Aiken (Tabel 3). Hasil revisi instrumen tes berdasarkan saran perbaikan dari validator disajikan oleh Tabel 4. Hasil uji validitas empiris melalui uji coba kepada 82 siswa kelas VII SMPN 3 Parung Panjang disajikan pada Tabel 5. 
Perhitungan reliabilitas instrumen disajikan pada Tabel 6. Hasil perhitungan terhadap tingkat kesukaran soal disajikan pada Tabel 7.

Tabel 3. Hasil Uji Validasi oleh Ahli

\begin{tabular}{|c|c|c|c|c|c|c|c|}
\hline \multirow{2}{*}{ KRITERIA } & \multirow{2}{*}{ No } & \multicolumn{2}{|c|}{ MATERI } & \multicolumn{2}{|c|}{ KONSTRUKSI } & \multicolumn{2}{|c|}{ BAHASA } \\
\hline & & Skor & Status & Skor & Status & Skor & Status \\
\hline \multirow{9}{*}{$\begin{array}{l}\text { Aspek Materi } \\
\text { Kesesuaian dimensi literasi } \\
\text { Biologi } \\
\text { Kesesuaian dengan indikator } \\
\text { Pilihan jawaban homogen dan } \\
\text { logis } \\
\text { Hanya terdapat satu kunci } \\
\text { jawaban }\end{array}$} & $\mathrm{S} 1$ & 0,88 & Sangat Valid & 0,80 & Sangat Valid & 0,94 & Sangat Valid \\
\hline & $\mathrm{S} 2$ & 0,88 & Sangat Valid & 0,84 & Sangat Valid & 0,94 & Sangat Valid \\
\hline & S3 & 0,81 & Sangat Valid & 0,84 & Sangat Valid & 0,94 & Sangat Valid \\
\hline & $\mathrm{S} 4$ & 0,86 & Sangat Valid & 0,83 & Sangat Valid & 0,91 & Sangat Valid \\
\hline & S5 & 0,88 & Sangat Valid & 0,88 & Sangat Valid & 0,94 & Sangat Valid \\
\hline & S6 & 0,86 & Sangat Valid & 0,83 & Sangat Valid & 0,91 & Sangat Valid \\
\hline & S7 & 0,88 & Sangat Valid & 0,86 & Sangat Valid & 0,88 & Sangat Valid \\
\hline & S8 & 0,95 & Sangat Valid & 0,86 & Sangat Valid & 0,94 & Sangat Valid \\
\hline & S9 & 0,83 & Sangat Valid & 0,80 & Sangat Valid & 0,88 & Sangat Valid \\
\hline \multirow{5}{*}{$\begin{array}{l}\text { Aspek Konstruksi Soal } \\
\text { Soal dirumuskan dengan jelas } \\
\text { dan tegas. } \\
\text { Soal mengandung petunjuk } \\
\text { kunci jawaban }\end{array}$} & S10 & 0,92 & Sangat Valid & 0,86 & Sangat Valid & 0,94 & Sangat Valid \\
\hline & S11 & 0,84 & Sangat Valid & 0,80 & Sangat Valid & 0,94 & Sangat Valid \\
\hline & S12 & 0,89 & Sangat Valid & 0,86 & Sangat Valid & 0,88 & Sangat Valid \\
\hline & S13 & 0,91 & Sangat Valid & 0,89 & Sangat Valid & 0,94 & Sangat Valid \\
\hline & S14 & 0,89 & Sangat Valid & 0,84 & Sangat Valid & 0,94 & Sangat Valid \\
\hline \multirow{4}{*}{$\begin{array}{l}\text { Gambar, tabel, artikel, } \\
\text { diagram berfungsi. } \\
\text { Soal bebas dari pernyataan } \\
\text { negatif }\end{array}$} & S15 & 0,84 & Sangat Valid & 0,84 & Sangat Valid & 0,94 & Sangat Valid \\
\hline & S16 & 0.91 & Sangat Valid & 0,89 & Sangat Valid & 0,94 & Sangat Valid \\
\hline & S17 & 0,91 & Sangat Valid & 0,88 & Sangat Valid & 0,94 & Sangat Valid \\
\hline & S18 & 0,81 & Sangat Valid & 0,78 & Valid & 0,94 & Sangat Valid \\
\hline \multirow{2}{*}{$\begin{array}{l}\text { ganda. } \\
\text { Aspek Bahasa } \\
\text { Sesuai dengan kaidah bahasa }\end{array}$} & S19 & 0,84 & Sangat Valid & 0,75 & Valid & 0,88 & Sangat Valid \\
\hline & S20 & 0,91 & Sangat Valid & 0,84 & Sangat Valid & 0,88 & Sangat Valid \\
\hline Indonesia. & & & & & & & \\
\hline $\begin{array}{l}\text { Menggunakan bahasa yang } \\
\text { komunikatif. }\end{array}$ & & & & & & & \\
\hline
\end{tabular}

Tabel 4. Contoh Revisi Soal dari Validator

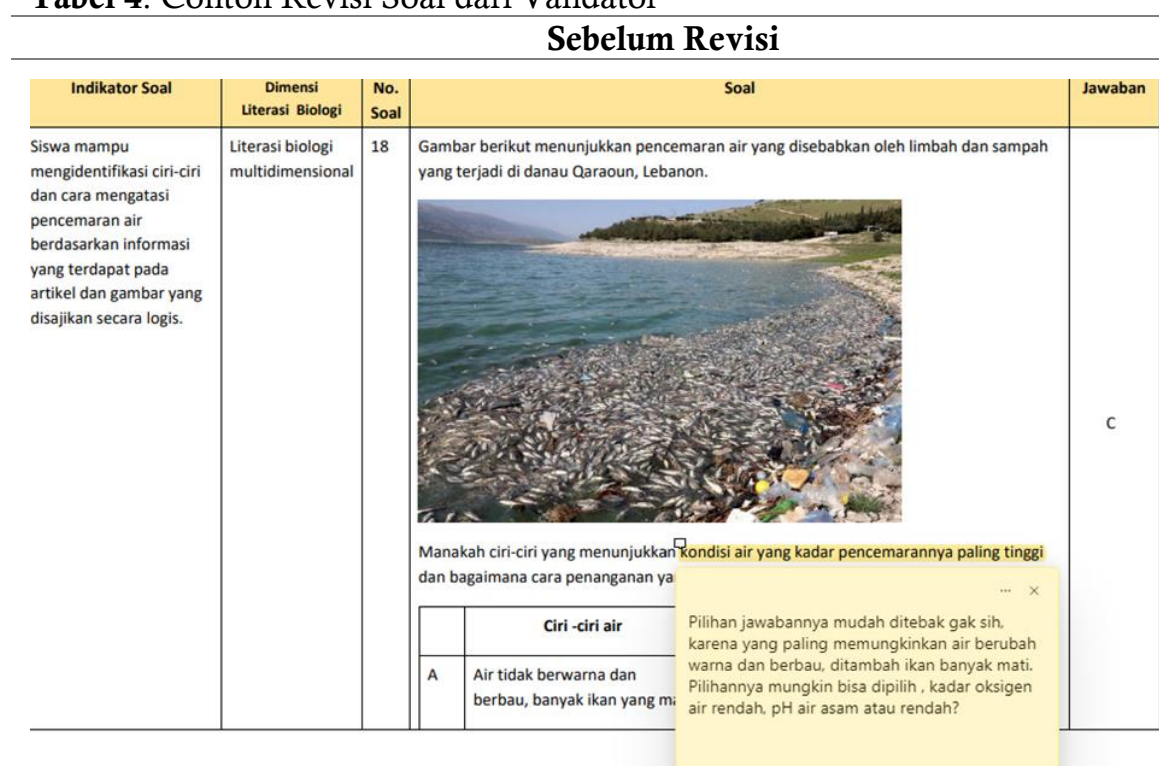

\section{Keterangan}

Revisi dari validator: pilihan jawaban mudah ditebak, gambar terlalu memberikan petunjuk jawaban. 


\section{Setelah Revisi}

Pencemaran air banyak terjadi di wilayah perairan di Indonesia. Gambar 1 dan 2 adalah dua buah danau yang terdapat di Indonesia. Salah satu danau airnya telah tercemar oleh sampah. Selain pencemaran karena sampah, perairan tawar juga dapat mengalami eutrofikasi. Eutrofikasi adalah salah satu kondisi perairan yang disebabkan oleh limbah fosfat yang terbawa bersama dengan aliran sungai. Eutrofikasi dapat diartikan sebagai pencemaran air karena munculnya nutrisi yang berlebihan pada ekosistem air. Kondisi ini dapat terjadi secara alami atau karena aktivitas manusia yang menyebabkan meningkatnya kadar fosfat di tanah. Fosfat di tanah ini lalu terbawa aliran air hujan ke danau/empang. Secara alami, proses air tawar sampai pada kondisi eutropik memerlukan waktu yang sama lama.

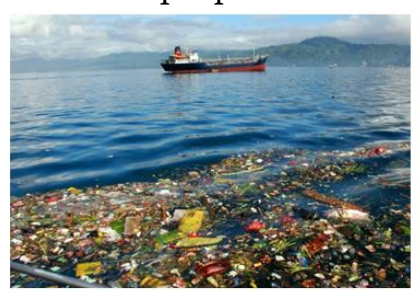

Gambar 1

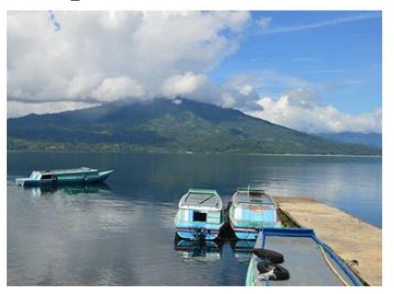

Gambar 2

\section{Keterangan}

Gambar

direvisi dan

diberikan

deskripsi soal

yang lebih

kontekstual.

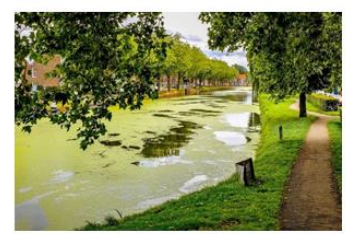

Gambar 3

Tabel 5. Hasil Uji Validitas Empiris kepada 82 Siswa

\begin{tabular}{cccccccc}
\hline No & rhitung & rtabel & Kesimpulan & No & rhitung & rtabel & Kesimpulan \\
\hline S1 & 0,35 & 0,183 & Valid & S11 & 0,30 & 0,183 & Valid \\
S2 & 0,35 & 0,183 & Valid & S12 & 0,23 & 0,183 & Valid \\
S3 & 0,29 & 0,183 & Valid & S13 & 0,21 & 0,183 & Valid \\
S4 & 0,39 & 0,183 & Valid & S14 & 0,38 & 0,183 & Valid \\
S5 & 0,46 & 0,183 & Valid & S15 & 0,17 & 0,183 & Tidak Valid \\
S6 & 0,39 & 0,183 & Valid & S16 & 0,36 & 0,183 & Valid \\
S7 & 0,20 & 0,183 & Valid & S17 & 0,42 & 0,183 & Valid \\
S8 & 0,37 & 0,183 & Valid & S18 & 0,29 & 0,183 & Valid \\
S9 & 0,41 & 0,183 & Valid & S19 & 0,25 & 0,183 & Valid \\
S10 & 0,25 & 0,183 & Valid & S20 & 0,45 & 0,183 & Valid \\
\hline
\end{tabular}

Tabel 6. Hasil Perhitungan Uji Reliabilitas dengan Kuder and Richardson Formula 20
Hasil perhitungan uji reliabilitas dengan KR- 20
$r=(n / n-1) \frac{\left(S t^{2}-\Sigma p q\right)}{S t^{2}}$
Keterangan:
$\mathrm{r}=$ koefisien reliabilitas
$\mathrm{n}=$ banyaknya butir soal
$\mathrm{p}=$ proposi jawaban benar butir soal ke-i
$\mathbf{r}=\mathbf{0 , 5 7 3}$ berarti bahwa instrumen ini cukup reliabel
$\mathrm{q}=$ proporsi jawaban salah butir soal ke-i
$s t^{2}=$ varians skor test

Tabel 7. Hasil Uji Tingkat Kesukaran Soal

\begin{tabular}{|c|c|c|c|c|c|}
\hline \multirow{2}{*}{ No } & \multicolumn{2}{|c|}{ Tingkat kesukaran } & \multirow{2}{*}{ No } & \multicolumn{2}{|c|}{ Tingkat kesukaran } \\
\hline & Skor & Kriteria & & Skor & Kriteria \\
\hline S1 & 0,49 & Sedang & S11 & 0,40 & Sedang \\
\hline S2 & 0,27 & Sukar & S12 & 0,39 & Sedang \\
\hline S3 & 0,30 & Sedang & S13 & 0,34 & Sedang \\
\hline
\end{tabular}




\begin{tabular}{cccccc}
\hline S4 & 0,37 & Sedang & S14 & 0,17 & Sukar \\
\hline S5 & 0,30 & Sedang & S15 & 0,56 & Sedang \\
\hline S6 & 0,29 & Sukar & S16 & 0,32 & Sedang \\
\hline S7 & 0,24 & Sukar & S17 & 0,26 & Sukar \\
\hline S8 & 0,22 & Sukar & S18 & 0,33 & Sedang \\
\hline S9 & 0,44 & Sedang & S19 & 0,39 & Sedang \\
\hline S10 & 0,50 & Sedang & S20 & 0,43 & Sedang \\
\hline
\end{tabular}

\section{Pembahasan}

Produk hasil pengembangan berupa instrumen tes berbasis literasi biologi pada materi biologi SMP kelas VII yang didesain sesuai dengan model pengembangan dari Dick and Carey. Instrumen tes yang dikembangkan, diuji validasinya, baik secara logis oleh ahli dan praktisi lapangan, maupun uji coba empiris kepada siswa. Validasi dilakukan oleh empat validator, dua orang merupakan dosen pendidikan biologi dan dosen ilmu komunikasi, dan dua orang praktisi lapangan yang berinteraksi langsung dengan siswa. Berdasarkan masukan dari validator, instrumen tes direvisi sehingga instrumen tes dengan layak untuk diujicobakan kepada siswa.

Persebaran kompetensi dasar, dimensi literasi Biologi disajikan pada Tabel 1. Cara penyajian butir soal pada instrumen ini tidak dilakukan berdasarkan urutan $\mathrm{KD}$. Pengelompokan soal dilakukan berdasarkan kesamaan karakter tertentu, sehingga soal-soal tersebut memiliki keterkaitan. Soal diberikan kepada siswa melalui Google form, beberapa soal yang memiliki keterkaitan disajikan dalam satu section. Contoh salah satu pengelompokan soal disajikan pada tabel 2 yang menunjukkan salah satu bagian (section) pada Google form. Section ini terdiri dari 5 soal yang merupakan gabungan dari $4 \mathrm{KD}$, yaitu $\mathrm{KD} 3.3$ mengenai klasifikasi makhluk hidup, KD 3.5 mengenai perubahan bentuk energi dan fotosintesis, KD 3.7 mengenai interaksi antar makhluk hidup dalam ekosistem dan KD 3.8 mengenai pencemaran lingkungan.

Soal pertama menyajikan berbagai grafik yang berisi data terkait dengan kasus nyata yang diambil dari artikel online. Grafik data yang disajikan merupakan data yang terkait dengan konsep permasalahan lingkungan yang terjadi di Indonesia. Penggunaan artikel dari media dapat berkontribusi dalam membangun kemampuan berpikir siswa (Akcay et al., 2017). Dimensi Biologi yang diujikan adalah dimensi multidimensional yang menguji kemampuan siswa dalam memahami interaksi biologi dengan aspek sosial. Salah satu grafik yang berupa angka kehilangan hutan primer di Indonesia, selanjutnya merupakan konteks yang digunakan untuk pertanyaan nomor dua sampai nomor lima pada section yang sama. Dengan menggunakan konteks ekosistem sebuah hutan, soal kedua menyajikan masalah penebangan hutan. Deskripsi masalah diberikan sebagai pengantar pertanyaan. Kemampuan siswa pada dimensi literasi biologi multidimensional untuk menganalisa dampak penebangan hutan terhadap manusia diujikan. Dimensi literasi biologi nominal diujikan pada soal ketiga berupa identifikasi hirarki interaksi makhluk hidup dan ekosistem hutan berdasarkan gambar yang diberikan. Soal keempat 
dan kelima merupakan dimensi literasi fungsional. Konsep yang diuji adalah penggunaan diagram dikotomi untuk menentukan klasifikasi salah satu hewan yang hidup di hutan dan proses fotosintesis yang dilakukan oleh tumbuhan yang hidup di dalam hutan.

Berdasarkan hasil uji validitas logis yang dinilai oleh validator dan hasil uji validitas empiris yang diujicobakan kepada siswa SMPN 3 Parung Panjang kelas VII diperoleh bahwa pengembangan instrumen tes ini layak diujicobakan untuk digunakan oleh siswa kelas VII SMP. Revisi dari validator pertama meliputi: 1) Perbaikan terhadap butir pilihan soal, 2) Pengelompokan soal -soal yang memiliki keterkaitan dengan konteks yang sama, 3) Perbaikan beberapa butir soal yang belum sesuai antara butir soal dengan aspek dimensi literasi biologinya. Berdasarkan masukan dan revisi dari semua validator, instrumen tes ini diperbaiki sebelum diujicobakan kepada siswa SMP kelas VII. Hasil kalkulasi dari penilaian keempat validator untuk validitas instrumen ini disajikan pada tabel 3 , sementara contoh revisi yang dilakukan berdasarkan masukan, disajikan pada Tabel 4.

Hasil validasi empiris disajikan pada Tabel 5. Uji coba validasi empiris butir soal skala kecil dilakukan di kelas VII SMPN 3 Parung Panjang dengan 82 siswa kelas VII subjek uji coba. Setelah dilakukan uji coba didapat hasil validitas butir skor ditentukan dengan menggunakan koefisien korelasi point biserial. Koefisien korelasi yang didapat untuk masing-masing butir dibandingkan dengan koefisien korelasi yang ada pada tabel-r dengan $\mathrm{df}=80$ pada alpha 0,05 pada uji dua arah diperoleh rtabel 0,183. Jika koefisien korelasi antara skor butir dengan skor total tes > rtabel maka butir tersebut valid berdasarkan ukuran validitas internal. Hasil koefisien korelasi point biserial setiap butir soal setelah dibandingkan dengan koefisien korelasi yang ada pada tabel r, maka diperoleh 19 dari 20 item soal yang bernilai valid. Sedangkan beberapa item soal yang tidak valid (rhitung di bawah 0.183 ) maka item tersebut harus diperbaiki atau dibuang (Sugiyono, 2019). Dalam penelitian ini item yang tidak valid dibuang, karena telah cukup mewakili setiap aspek dalam instrumen tes. Penilaian dari soal yang dikembangkan, seperti disajikan pada Tabel 5, terdapat 19 soal valid dari 20 soal yang dikembangkan. Instrumen ini memiliki koefisien reliabilitas sebesar 0,573 yang berarti cukup reliabel (Tabel 6).

Uji tingkat kesukaran soal berdasarkan hasil uji dihitung dan disajikan pada Tabel 7. Berdasarkan perhitungan, diperoleh dua kategori dalam tingkat kesukaran, yaitu sukar dan sedang. Tingkat kesukaran butir soal adalah proporsi antara banyaknya peserta tes yang merespon butir soal dengan jawaban benar dengan jumlah dari banyaknya peserta tes (Hanifah, 2014). Hal ini dapat diartikan bahwa semakin peserta tes banyak yang merespon butir soal dengan benar maka akan semakin besar indeks dari tingkat kesukaran yang berarti mengungkapkan semakin mudahnya butir soal tersebut. Sedangkan apabila semakin peserta tes sedikit yang menjawab butir soal dengan benar maka dapat diartikan bahwa soal tersebut adalah 
semakin sukar. Pada tabel tersebut terdapat 14 butir soal termasuk tingkat kesukarannya sedang dan 6 butir soal termasuk tingkat kesukarannya adalah sukar.

\section{SIMPULAN}

Penelitian pengembangan ini menggunakan model Dick dan Carey (1996) yaitu model ADDIE yang hanya mengambil 3 tahap yaitu analyze, design, dan development. Berdasarkan hasil rekapitulasi dapat disimpulkan instrumen tes literasi biologi siswa pada aspek dimensi nominal, fungsional, struktural dan multidimensional untuk SMP kelas VII yang dikembangkan dalam penelitian ini mempunyai tingkat validitas 19 butir soal valid dari 20 butir soal. Reliabilitas instrumen tes mempunyai koefisien reliabilitas 0,57 dengan interpretasi yaitu cukup reliabel. Untuk tingkat kesukaran diperoleh terdapat 14 butir soal termasuk tingkat kesukarannya sedang dan 6 butir soal termasuk tingkat kesukarannya adalah sukar. Maka dapat disimpulkan bahwa instrumen tes literasi biologi yang dikembangkan layak untuk diujicobakan atau diimplementasikan kepada tahap selanjutnya dari model ADDIE. Dan setelah melakukan penelitian ini peneliti menyarankan agar adanya penelitian yang lebih lanjut untuk menyempurnakan instrumen penilaian literasi biologi siswa dan melakukan penilaian literasi biologi pada skala yang lebih besar.

\section{UCAPAN TERIMA KASIH}

Ucapan terima kasih disampaikan kepada keempat validator yang membantu memvalidasi instrumen literasi biologi ini, yaitu 1) Ibu Dra. Jeane Budiwati Tjandiagung, M.Rur. Sc. yang berpengalaman sebagai kepala bidang IPA Departemen Penelitian dan Pengembangan Sekolah Santa Laurensia, 2) Ibu Dra. Destri Nudyawati, M.Pd. selaku praktisi lapangan yang berpengalaman sebagai kepala sekolah, wakasek bidang kurikulum dan guru biologi di SMA Santa Laurensia, 3) Ibu Dina Rahma Fadlilah, M.Si. sebagai dosen pendidikan biologi di Universitas Islam Negeri Syarif Hidayatullah Jakarta, dan 4) Bapak Catur Nugroho, S.Sos., M.Ikom sebagai dosen ilmu komunikasi di Telkom University Bandung yang juga berpengalaman dalam literasi digital.

\section{REFERENSI}

Akcay, H., Kapici, H. O., \& Yager, R. E. (2017). Using Newspapers and Advertisement as a Focus for Science Teaching and Learning. Universal Journal of Education Research, 5(1), 99103. https://doi.org/10.13189/ujer.2017.050112

Aiken, L. R. (1980). Content Validity and Reliability of Single Items or Questionnaires. Educational and Psychological Measurement. https://doi.org/10.1177/001316448004000419

Atta, H. B., Vlorensius, Aras, I., \& Ikhsanudin. (2020). Developing an instrument for students scientific literacy. Journal of Physiscs:Conference Series, 1422. https://doi.org/10.1088/17426596/1422/1/012019 
Asrizal, A., Festiyed, F., \& Sumarmin, R. (2017). Analisis Kebutuhan Pengembangan Bahan Ajar Ipa Terpadu Bermuatan Literasi Era Digital Untuk Pembelajaran Siswa Smp Kelas Viii. Jurnal Eksakta Pendidikan (Jep), 1(1), 1. https://doi.org/10.24036/jep/vol1-iss1/27

Branch, R. M. (2021). Instructional Design: The ADDIE Approach. In Encyclopedia of Evolutionary Psychological Science. Springer. https://doi.org/10.1007/978-3-319-196503_2438

Dawati, F. M., Yamtinah, S., Rahardjo, S. B., Ashadi, \& Indriyanti, N. Y. (2017). Uji Validitas Computerized Two-Tier Multiple Choice ( CTTMC ) Melalui Focus Group Discussion ( FGD ) Untuk Mendiagnosis Kesulitan Belajar Siswa. Seminar Nasional Pendidikan Sains Universitas Sebelas Maret, 21, 260-265.

Demastes, S., \& Wandersee, J. H. (1992). Biological Literacy in a College Biology Classroom. BioScience, 42(1), 63-65. https://doi.org/10.2307/1311631

Djamahar, R., Rifan, M., \& Ristanto, R. H. (2021). Bio-repropedia website based on reading, mapping, and sharing (RMS): A way to improve biological literacy. IOP Conference Series: Earth and Environmental Science, 1796(1). https://doi.org/10.1088/17426596/1796/1/012067

Fahmina, S. S., Indriyanti, N. Y., Setyowati, W. A. E., \& Masykuri, M. (2019). Dimension of Chemical Literacy and its Influence in Chemistry Learning. Journal of Physics:Conference Series. https://doi.org/10.1088/1742-6596/1233/1/012026

Greenleaf, C. L., Litman, C., Hanson, T. L., Rosen, R., Boscardin, C. K., Herman, J., Schneider, S. A., Madden, S., \& Jones, B. (2011). Integrating Literacy and Science in Biology. American Educational Research Journal, 48(3), 647-717. https://doi.org/10.3102/0002831210384839

Hanifah, N. (2014). Perbandingan Tingkat Kesukaran, Daya Pembeda Butir Soal Pilihan Ganda Biasa dan Pilihan Ganda Asosiasi Mata Pelajaran Ekonomi. SOSIO E-KONS, 6(1), 41-55. https://journal.lppmunindra.ac.id/index.php/sosio_ekons/article/viewFile/1715/1321

Hasana, I., Saptasari, M., \& Wulandari, N. (2017). Pengembangan Instrumen Penilaian Kemampuan Literasi Sains Siswa Kelas XI Materi Sistem Ekskresi dan Koordinasi di SMAN 9 Malang. Jurnal Pendidikan Biologi, 8(2), 52-56.

Lasminawati, E., Lestari, N., Setiadi, D., \& Jufri, A. W. (2019). Analisis Cakupan Literasi Sains Dalam Buku Pelajaran Biologi Pegangan Siswa Kelas XI Kurikulum 2013. Jurnal Pijar Mipa, 14(2). https://doi.org/10.29303/jpm.v14i2.1233

Lina, Y. R., Helendra, \& Arsih, F. (2018). Pengembangan Instrumen Asesmen Berbasis Literasi Sains tentang Materi Sistem Pencernaan Makanan, Zat Aditif, dan Zat Adiktif untuk SMP. Bioeducation Journal, 2(2), 145-155.

McBride, B. B., Brewer, C. A., Berkowitz, A. R., \& Borrie, W. T. (2013). Environmental literacy, ecological literacy, ecoliteracy: What do we mean and how did we get here? Ecosphere, 4(5). https://doi.org/10.1890/ES13-00075.1

McFarlane, D. A. (2013). Understanding the Challenges of Science Education in the $21^{\text {st }}$ Century: New Opportunities for Scientific Literacy. International Letters of Social and Humanistic Sciences, 4, 35-44. https://doi.org/10.18052/www.scipress.com/ilshs.4.35

Novanti, S. K. E., Yulianti, E., \& Mustikasari, V. R. (2018). Pengembangan Instrumen Tes Literasi Sains Siswa SMP Materi Tekanan Zat dan Penerapannya dalam Kehidupan Sehari-hari. Jurnal Pembelajaran Sains, 2(2009), 6-12. http://journal2.um.ac.id/index.php/jpsi/ 
Novaristiana, R., Rinanto, Y., \& Ramli, M. (2019). Scientific literacy profile in biological science of high school students. Jurnal Pendidikan Biologi Indonesia, 5(1), 9-16. https://doi.org/10.22219/jpbi.v5i1.7080

Oliveras, B., Marquez, C., \& Sanmarti, N. (2011). The use of newspaper articles as a tool to develop critical thinking in science classes. International Journal of Science Education, Taylor \& Francis (Routledge), 1. https://doi.org/10.1080/09500693.2011.586736

Putri, R. K. (2020). Pengembangan Instrumen Tes Literasi Sains Siswa pada Topik Keanekaragaman Makhluk Hidup. Diklabio:Jurnal Pendidikan Dan Pembelajaran Biologi, 4(1), 71-78.

Penick, J. E. (1993). Scientific Literacy: An Annotated Bibliography. The ICASU/UNESCO Conference Project 2000+:Science Literacy for All, 1-328.

Rachmatullah, A., Diana, S., \& Rustaman, N. Y. (2016). Profile of middle school students on scientific literacy achievements by using scientific literacy assessments (SLA). AIP Conference Proceedings, 1708(February 2016). https://doi.org/10.1063/1.4941194

Rachmawati, R., \& Kurniawati, A. (2020). Pengembangan Instrumen Penilaian Tes Berbasis Mobile Online Pada Prodi Pendidikan Matematika. Prima: Jurnal Pendidikan Matematika, 4(1), 46. https://doi.org/10.31000/prima.v4i1.1891

Retnawati, H. (2016). Analisis Kuantitatif Instrumen Penelitian (Panduan peneliti, Mahasiswa dan Psikometrian). Parama Publisihing.

Retnawati, H. (2016). Proving Content Validity of Self-Regulated Learning Scale(The Comparison of Aiken and Expanded Gregory Index). Research and Evaluation in Education, 2(2), 155-164. https://doi.org/10.21831/reid.v2i2.11029

Seddon, M. (2017). Strategies for integrating literacy into a science classroom [University of Northern Iowa]. In Graduate Research Papers. https://scholarworks.uni.edu/grp/115

Setiawan, A. R. (2019). Instrumen Penilaian untuk Pembelajaran Ekologi Berorientasi Literasi Saintifik. Indonesian Journal of Biology Education, 7260(2), 42-46. http://ejournal.upi.edu/index.php/asimilasi\%0AInstrumen

Setiawan, A. R. (2019). Peningkatan literasi sientific melalui pembelajaran biologi melalui pembelajaran sientific. Journal of Biology Education IAIN KUDUS, 2, 223-235. https://doi.org/10.21043/jobe.v2i1.5278

Setiawan, A. R., \& Mufassaroh, A. Z. (2019). Menyusun Soal Literasi Saintifik untuk Pembelajaran Biologi Topik Plantae dan Animalia. Biosfer, J.Bio.\& Pend.Bio., 4(1).

Shwartz, Y., Ben-Zvi, R., \& Hofstein, A. (2006). The use of scientific literacy taxonomy for assessing the development of chemical literacy among high-school students. Chemistry Education Research and Practice, 7(4), 203-225. https://doi.org/10.1039/B6RP90011A

Sugiyono. (2019). Statistika untuk Penelitian (cetakan ke-30 ed.). Bandung: Penerbit Alfabeta.

Suprapto, N. (2016). What should educational reform in Indonesia look like?-Learning from the PISA science scores of East-Asian countries and Singapore Bilingual e-Book development (Beboo) View project The Effect of Conception of Physics' Learning, Content Knowledge, Pedagogi. Asia-Pacific Forum on Science Learning and Teaching, 17(2), 1. https://www.researchgate.net/publication/314645046

Suwarto. (2013). Pengembangan Tes Diagnostik dalam Pembelajaran. Panduan Praktis Bagi Pendidik dan Calom Pendidik (Cetakan ketiga ed.). Yogyakarta: Pustaka Pelajar.

Suwono, H., Pratiwi, H. E., Susanto, H., \& Susilo, H. (2017). Enhancement of students' biological literacy and critical thinking of biology through socio-biological case-based 
learning. Jurnal Pendidikan IPA Indonesia, 6(2), 213-222. https://doi.org/10.15294/jpii.v6i2.9622

Uno, G. E., \& Bybee, R. W. (1994). Understanding the Dimensions of Biological Literacy. BioScience, 44(8), 553-557. https://doi.org/10.2307/1312283

Wahyu, E., Fathurohman, A., \& Markos, S. (2016). Analisis Buku Siswa Mata Pelajaran IPA Kelas VIII SMP/MTs Berdasarkan Kategori Literasi Sains. Jurnal Inovasi Dan Pembelajaran Fisika, 3(2), 14-24. http://fkip.ac.id/index.php/menu/1

Yenni, R., Hernani, \& Widodo, A. (2017). The implementation of integrated science teaching materials based socio-scientific issues to improve students scientific literacy for environmental pollution theme. AIP Conference Proceedings, 1848. https://doi.org/10.1063/1.4983970 